\title{
A Study on Tensile and Shear behaviour of Untreated and Cryogenically Treated Al-SiC and Al-Gr Metal Matrix Composite
}

\author{
Arunkumar K. N. ${ }^{1 *}$, G. B. Krishnappa ${ }^{1}$ and Mohammed Salman Pasha ${ }^{1}$ \\ ${ }^{1}$ Department of Mechanical Engineering, VVCE, Mysuru - 570002, INDIA,
}

\begin{abstract}
The present study aims at evaluating the shear and tensile behaviour of untreated and cryogenically treated aluminium-silicon carbide and aluminium graphite metal matrix composite. In this composite Al6061 is used as matrix material with varying Silicon carbide quantity from $2.5 \mathrm{wt} \%$ to $10 \mathrm{wt} \%$ and also varying the quantity of graphite from $1 \mathrm{wt} \%$ to $4 \mathrm{wt} \%$. The composites used for this study were fabricated using stir casting technique. Electron dispersive X-ray spectroscopy and X-ray diffraction tests were carried out to know the composition and phase identification of the composite sample. Microstructure analysis was carried out to study the structure of the composites with and without cryogenic treatment.
\end{abstract}

Keywords: A16061+SiC, A16061+Gr, Cryogenic treatment.

\section{Introduction}

\subsection{Composites}

In recent decades, composite materials have effectively submitted the customary materials in a few light weight and high quality applicants. A composite material is a material system composed of two or more physically distinct phases, the properties of a composite as a whole are enhanced as compared with the properties its components. Composite material consists of two phases, primary phase and secondary phase. Matrix forms the primary phase within which secondary phase is imbedded. The embedment is also known as reinforcement or secondary phase.

\subsection{Metal Matrix Composite}

Metal Matrix composite is metal reinforced with other metal, particulate or fibres of ceramics materials. These are advanced materials giving properties that have not accomplished by customary materials. MMCs are generally prepared by dispersing the reinforcements in metal matrix. The alloys of aluminium, magnesium, titanium, and copper,

\footnotetext{
*Corresponding author: arunkn.10@vvce.ac.in
} 
are chosen as matrix material. The reinforcement is in the form of both continuous and discontinuous fibres, whiskers, and particulates.

\subsection{Aluminium Metal Matrix Composites}

Aluminium metal matrix composites are light weight and high performance aluminium centric material system. Aluminium metal matrix composites generally utilized in high-tech structural and functional applications including defence, aerospace, automotive, and thermal management areas and sports. AMCs are anticipated to replace monolithic materials incorporating aluminium alloys, ferrous alloys, titanium alloys and polymer based composites in a number of appliances.

\subsection{Fabrication of Metal Matrix Composites}

There is an extensive choice of creation methods in favour of composite materials yet here emphasis will be on the creation of MMCs and particularly particulate reinforced composites.

On the account of creation of MMC's, there are two stages existing. They are: matrix phase and reinforcement phase. Metal or an alloy of a base metal constitute matrix phase and the ceramic generally stand for reinforcement phase. Mechanically combined matrix and reinforcement is called MMCs. If it is not mixed mechanically, the product will be an alloy, not a composite material.

\subsection{Cryogenics}

The utilization of thermal treatments to enhance mechanical properties of metal components is an antiquated craftsmanship from the previous eras and is used till date. The treatments that are applied to metals to enhance mechanical properties are in a choice of temperature higher than the room temperature. Since few decades, attention has been shown in the cause of sub-zero treatment on the performance of metals. Sub-zero treatment is generally classified as either cold treatment down to dry ice temperature $193 \mathrm{k}$ or deep cryogenic treatment at near liquid nitrogen temperature $77 \mathrm{k}$.

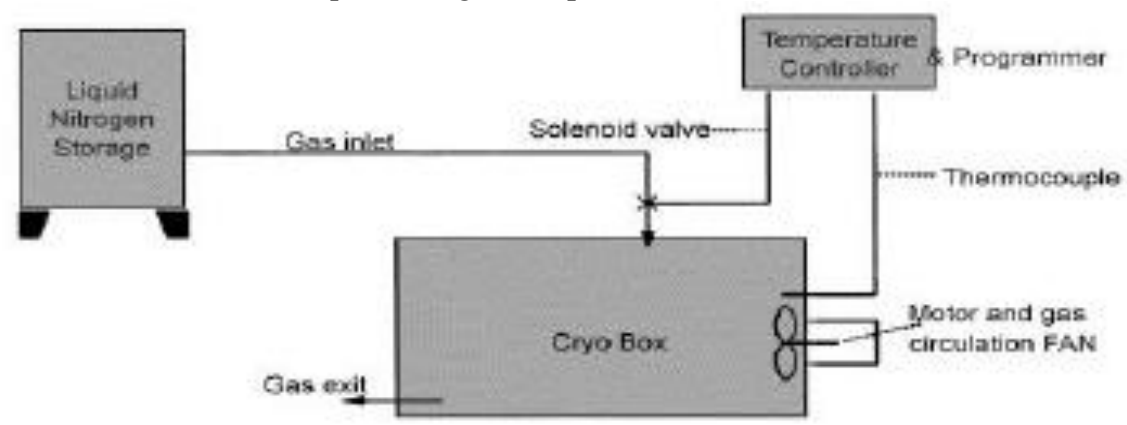

Fig. 1. Cryogenic Treatment Equipment 


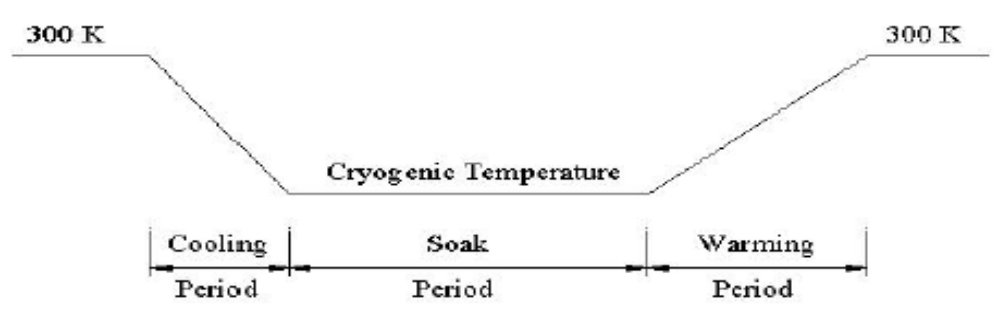

Fig. 2. Cryogenic Treatment Cycle

Cryogenic treatment imparts no visible changes in the metal after treatment. Despite the fact that it is unrealistic to observe external physical changes in the metal, a more uniform and refined microstructure with greater density is observed through metallurgical microscopes.

Typically, cryogenic treatment cycle comprises of cooling the test specimens from room temperature to cryogenic temperature in around 4 hours followed by soaking it at cryogenic temperature (normally liquid nitrogen temperature) for around 24hours and then warming it to room temperature for about 9hours. The soak temperature and duration are to a great extent in charge of changes in the properties after cryogenic treatment.

\section{Materials Used}

\subsection{Materials}

The raw materials as well as reinforcement materials used in synthesis of AMMCs are briefly described below.

\subsubsection{A/6061}

The aluminium Al6061 grade was utilized as the matrix material. Still some compelling studies are being conducted on aluminium alloys. It has low density, which gives additional positive circumstances in a couple of utilizations. Cast iron and Bronze have been supplanted by aluminium alloys to make wear resistance parts. 
Table 1. Chemical Composition of Al6061 by Wt $\%$

\begin{tabular}{|c|c|c|}
\hline Elements & Percentage & \\
\hline $\mathrm{Al}$ & 97.01 & \\
\hline $\mathrm{Mg}$ & 0.88 & oret \\
\hline $\mathrm{Si}$ & 0.71 & \\
\hline $\mathrm{Fe}$ & 0.64 & 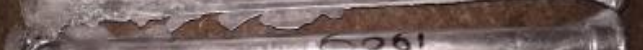 \\
\hline $\mathrm{Cu}$ & 0.23 & (3) \\
\hline $\mathrm{Cr}$ & 0.15 & 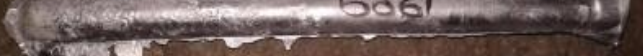 \\
\hline $\mathrm{Ti}$ & 0.04 & \\
\hline $\mathrm{Zn}$ & 0.09 & SOE \\
\hline $\mathrm{Mn}$ & 0.11 & \\
\hline
\end{tabular}

Fig. 3. Aluminium 6061 Ingot

\subsubsection{Silicon Carbide}

Silicon carbide (Sic) can be utilized as a reinforcement in the form of particulars, whiskers or fibres to enhance the properties of the composite. SiC improves the overall strength of the composites along with very high wear resistance and corrosion. The wear resistance of carbides is very high, therefore the wear resistance of material obtained is also high. Also, the hardness of the composites will increase. SiC are harder than Aluminium metals. If we add $\mathrm{SiC}$ in aluminium then it increases the stiffness of the material. After adding hard reinforcement, it resulted in improvement in resistance to wear and abrasion of the material. Content of $\mathrm{SiC}$ in material must be carefully added to avoid problem of grain boundaries, embrittlement and cracks formations.

Table 2. Properties of Silicon Carbide (SiC)

\begin{tabular}{|l|c|}
\hline Properties & Values \\
\hline Elastic Modulus(Gpa) & 410 \\
\hline Density(g/cc) & 3.1 \\
\hline Poisson's ratio & 0.14 \\
\hline Hardness(HB500) & 2800 \\
\hline Compression Strength(Mpa) & 3900 \\
\hline Melting temperature $\left({ }^{\circ} \mathrm{C}\right)$ & 3100 \\
\hline
\end{tabular}

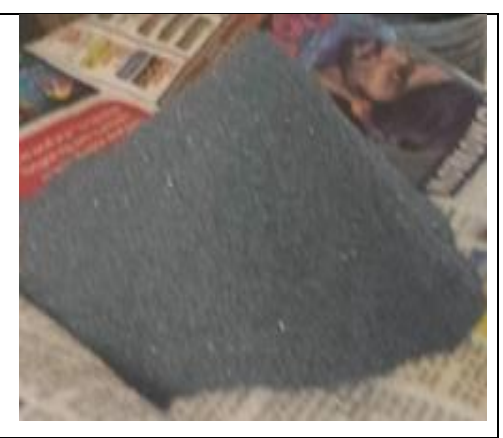

Fig. 4. Silicon Carbide Powder

\subsubsection{Graphite}

Graphite is a crystalline form of carbon having a layered structure with sheets of closely arranged carbon atoms. Consequently, graphite is fragile when sheared along the layers. This characteristic in turn gives graphite its low frictional properties as a solid lubricant. Its frictional properties are low only in an air or moisture. Unlike other materials, strength and stiffness of graphite increases with temperature. 


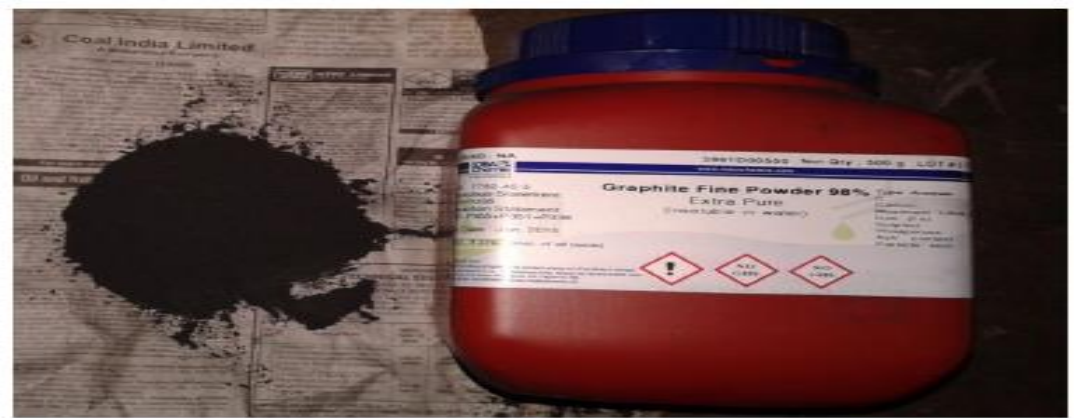

Fig. 5. Graphite Powder

\section{Methodology Flow}

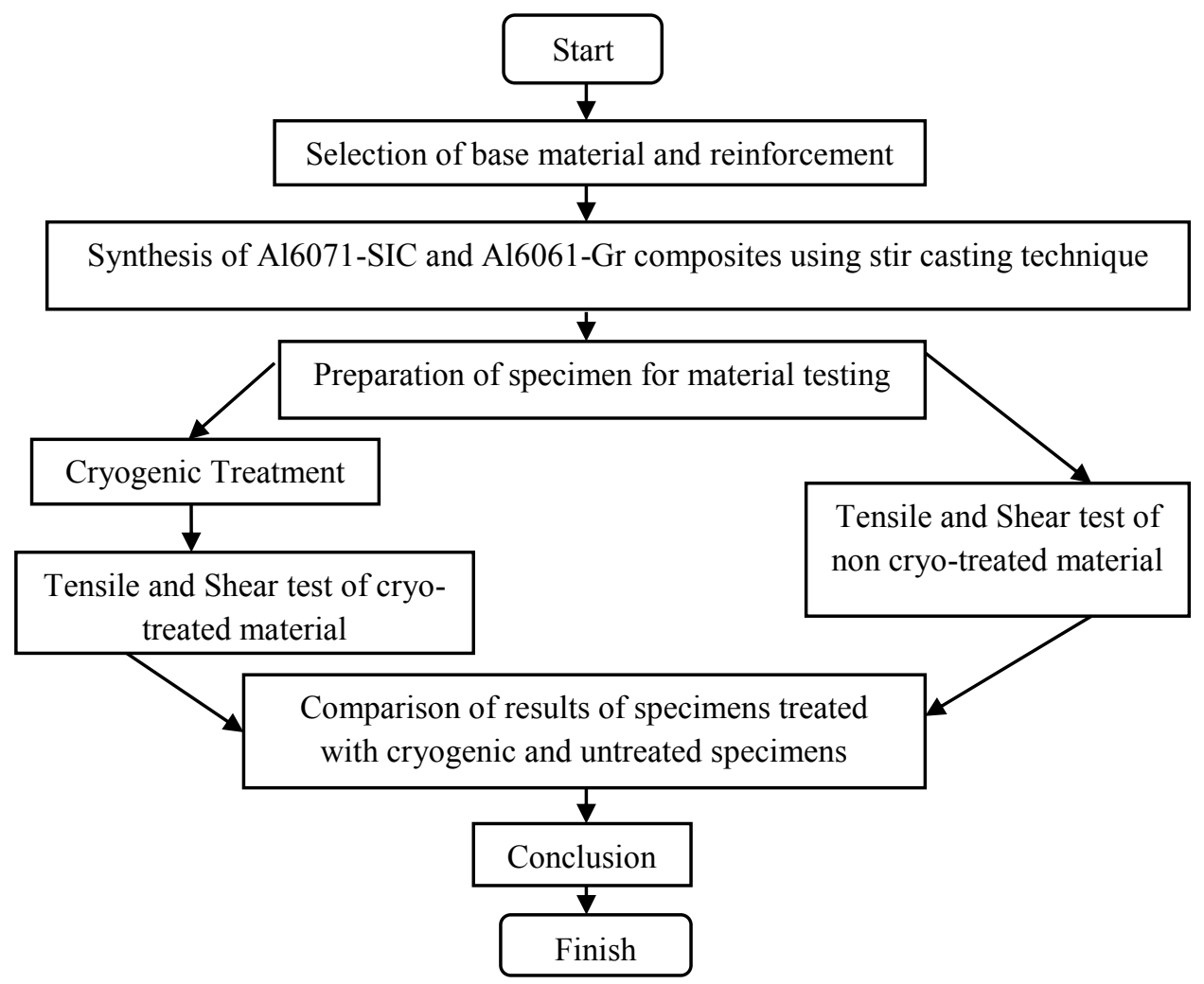

Fig. 6. Method Flow Chart

\section{Preparation of Composites}

Stir casting is utilized to fabricate the AMMCs specimens with multiple weight fractions of $\mathrm{SiC}$ and $\mathrm{Gr}$ particles as shown in table 4.1. Al6061 alloy is taken as matrix material. SiC and $\mathrm{Gr}$ are used as reinforcements. Aluminium alloy is reduced to molten state in the furnace and then preheated reinforcement particles are added. The composites are prepared 
by stir casting technique. The furnace used for fabrication is shown in fig 6 . The required composition was initially obtained by raw ingots and those ingots were melted at $800^{\circ} \mathrm{C}$ for almost 120 minutes in stir casting machine.

Table 3. Weight fraction of SiC and Gr in Al6061

\begin{tabular}{|l|l|l|l|}
\hline $\begin{array}{l}\text { SL } \\
\text { No. }\end{array}$ & Aluminium & $\begin{array}{l}\text { Silicon } \\
\text { Carbide }\end{array}$ & Graphite \\
\hline 1. & $\mathrm{~A} 16061$ & $2.5 \% \mathrm{SiC}$ & $1 \% \mathrm{Gr}$ \\
\hline 2. & $\mathrm{~A} 16061$ & $5 \% \mathrm{SiC}$ & $2 \% \mathrm{Gr}$ \\
\hline 3. & $\mathrm{~A} 16061$ & $7.5 \% \mathrm{SiC}$ & $3 \% \mathrm{Gr}$ \\
\hline 4. & $\mathrm{~A} 16061$ & $10 \% \mathrm{SiC}$ & $4 \% \mathrm{Gr}$ \\
\hline
\end{tabular}

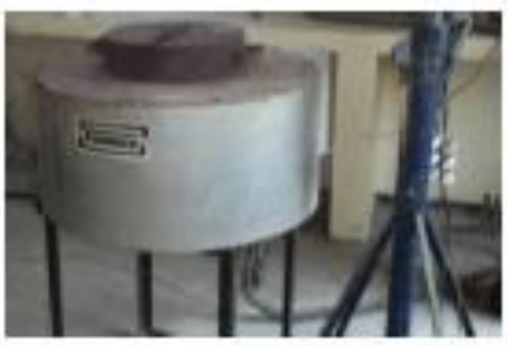

Fig. 7. Furnace

\section{Tensile and Shear Test}

Tensile test and shear test were carried out on the AMMCs separately. For tensile test ASTM E8 standard was followed. Similarly for the shear test specimen size of $85 \mathrm{~mm}$ length and $10 \mathrm{~mm}$ diameter was used.

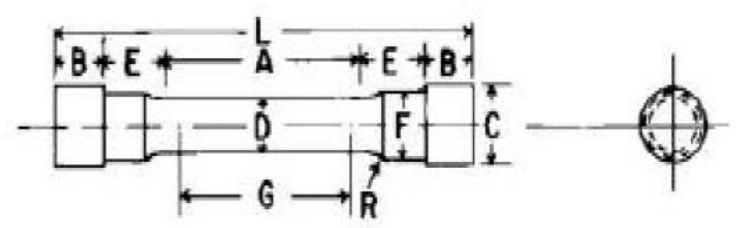

Fig. 8. ASTM E8 standard

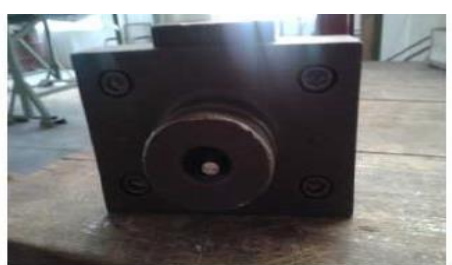

Fig. 9. Shear box

\section{Results and Discussion}

\subsection{Scanning Electron Microstructure}

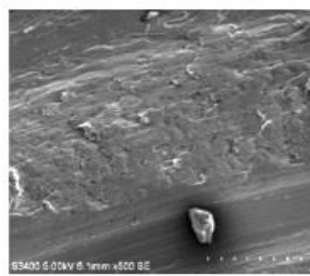

(a)

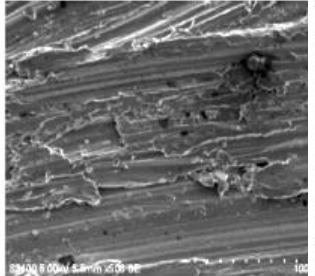

(b)

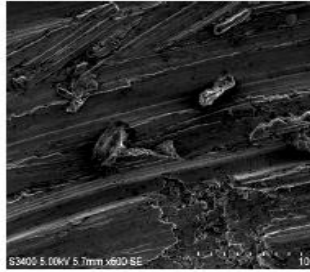

(c)

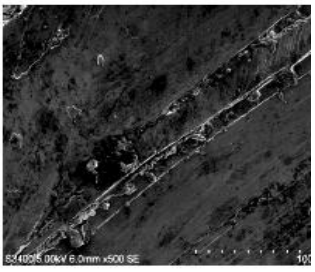

(d)

Fig. 10. SEM of Untreated (a) Al6061+2\% Gr (d) $\mathrm{A} 16061+10 \% \mathrm{SiC}$

(c) $\mathrm{Al} 6061+5 \% \mathrm{SiC}$ 


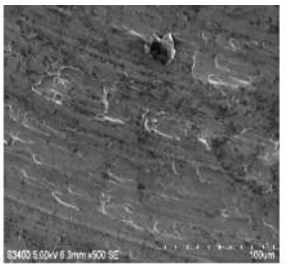

(a)

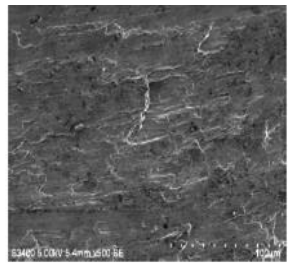

(b)

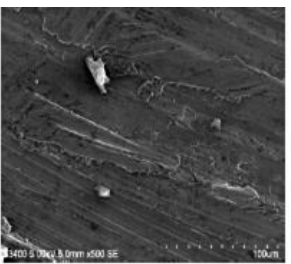

(c)

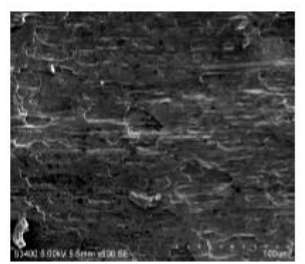

(d)

Fig. 11. SEM of Cryo-treated (a) Al6061+2\% Gr (b) Al6061+4\% Gr (c) Al6061+5\% SiC (d) $\mathrm{Al} 6061+10 \% \mathrm{SiC}$

\subsection{Shear test}

Shear test has been carried out using universal testing mahine(UTM) with the specimen of dimension $85 \mathrm{~mm}$ length, $10 \mathrm{~mm}$ diameter and cross sectional area of $78.53 \mathrm{~mm}^{2}$

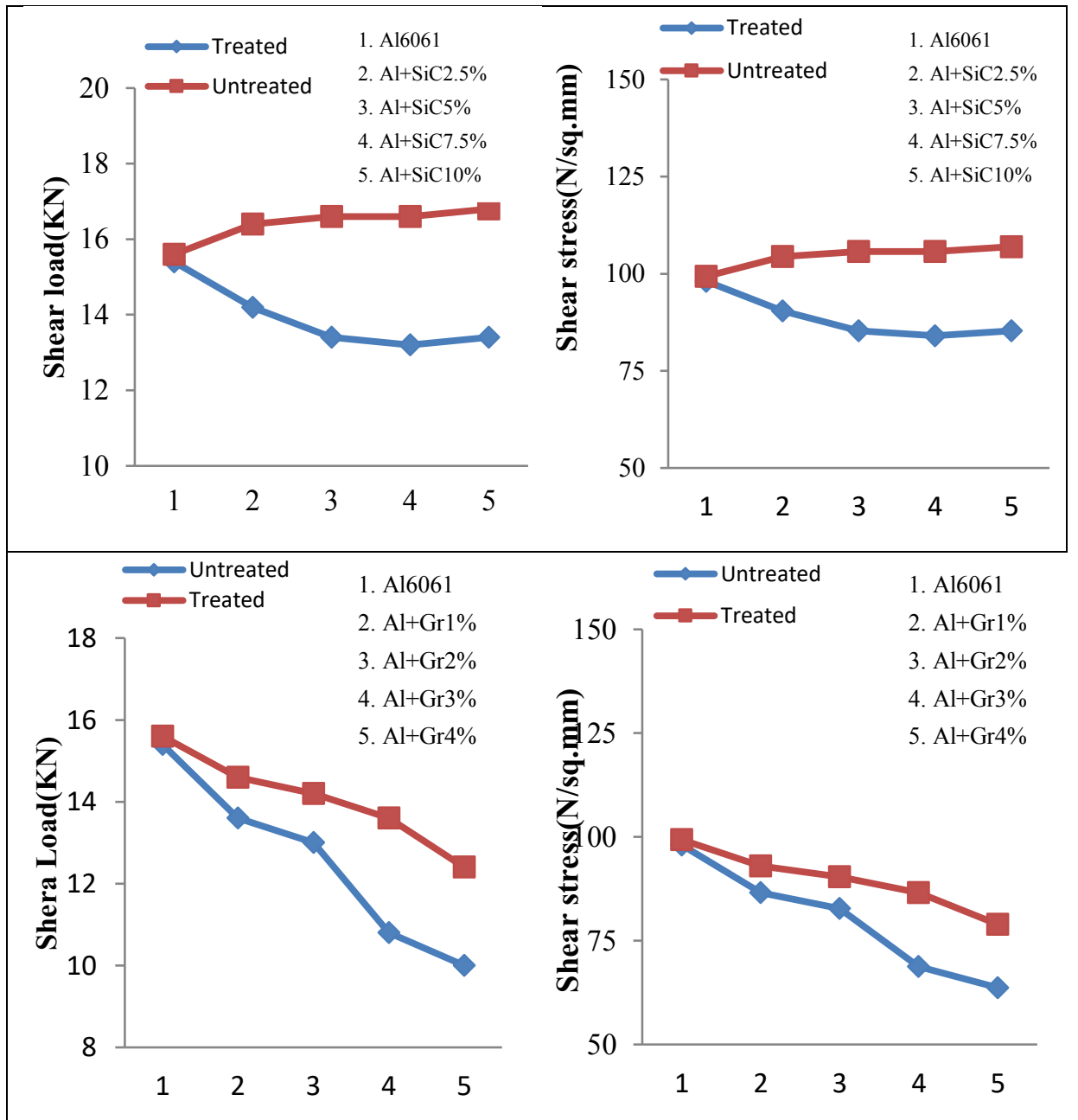

Fig. 12. Comparison of shear load for $\mathrm{Al}+\mathrm{SiC}$ and $\mathrm{Al}+\mathrm{Gr} \mathrm{AMMCs}$
Fig. 13. Comparison of Shear stress for $\mathrm{Al}+\mathrm{SiC}$ and $\mathrm{Al}+\mathrm{Gr} \mathrm{AMMCs}$ 


\subsection{Energy Dispersive Spectroscopy(EDS) Analysis:}

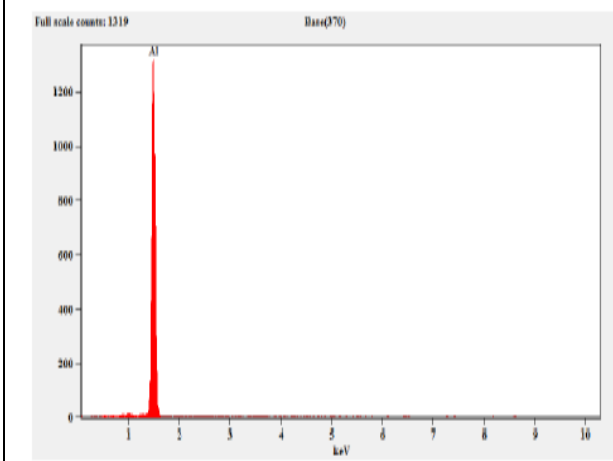

(a)

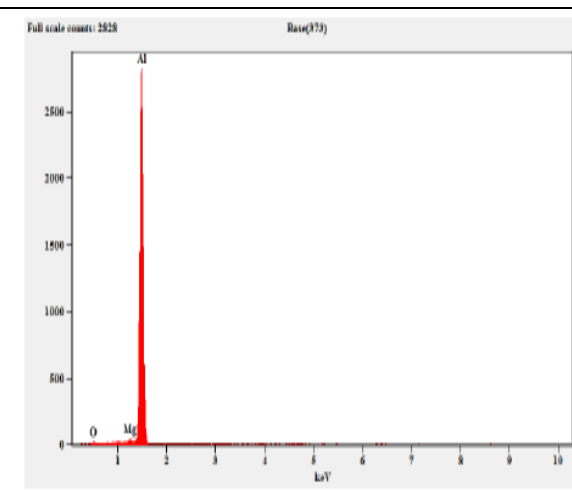

(c)

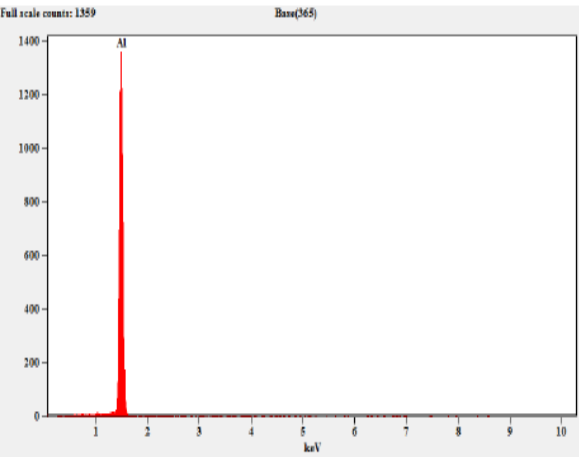

(b)

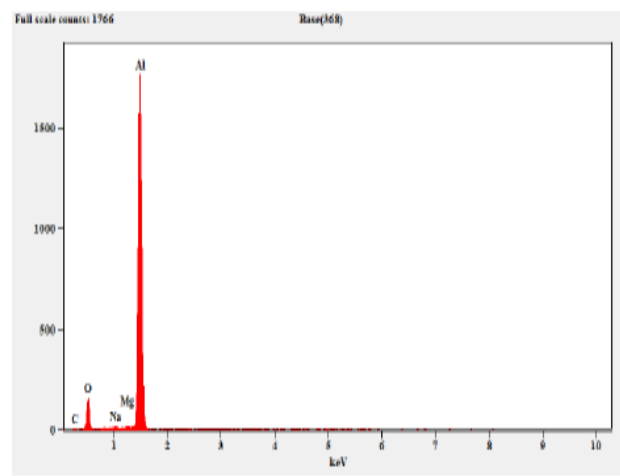

(d)

Fig. 14. EDS of (a) Untreated Al6061+ $2 \% \mathrm{Gr}$ (b) Cryo-treated Al6061+2\%Gr (c) Untreated $\mathrm{A} 16061+5 \% \mathrm{SiC}$ (d) Cryo-treated $\mathrm{Al} 6061+5 \% \mathrm{SiC}$

Energy dispersive spectroscopy analysis of the Al6061 reinforced with $\mathrm{Gr}$ and $\mathrm{SiC}$ with weight fraction of $2 \%$ and $5 \%$ respectively. It is shown that $\mathrm{Al}, \mathrm{Si}, \mathrm{O}$ and $\mathrm{C}$ peaks the graph and EDS analysis depicts the presence of AL6061, $\mathrm{SiC}, \mathrm{Gr}$ particles. The $\mathrm{Mg}_{2} \mathrm{Si}$ (magnesium silicate) and $\mathrm{SiO}_{2}$ (silicon oxide) are the products of reaction which shown as $\mathrm{Mg}$ and Si peaks in EDS graph after cryogenic treatment.

\subsection{Tensile Test}

The Peak load recorded for untreated Al6061 specimen was 1092.6 N. The highest peak load recorded for cryo-treated Al6061 was $1176.8 \mathrm{~N}$. Al6061+7.5\% SiC was found to best among the combinations.

Similarly, the highest break load recorded for untreated for unwanted specimen was $690.6 \mathrm{~N}$. The highest break load for cryo-treated specimen was found to be $784.6 \mathrm{~N}$. Compared to untreated specimen, cryo-treated specimen has higher value of break load which indicates that cryo treatment improves strength of the specimen. Al6061+7.5\% SiC was found to be best among the combinations. 


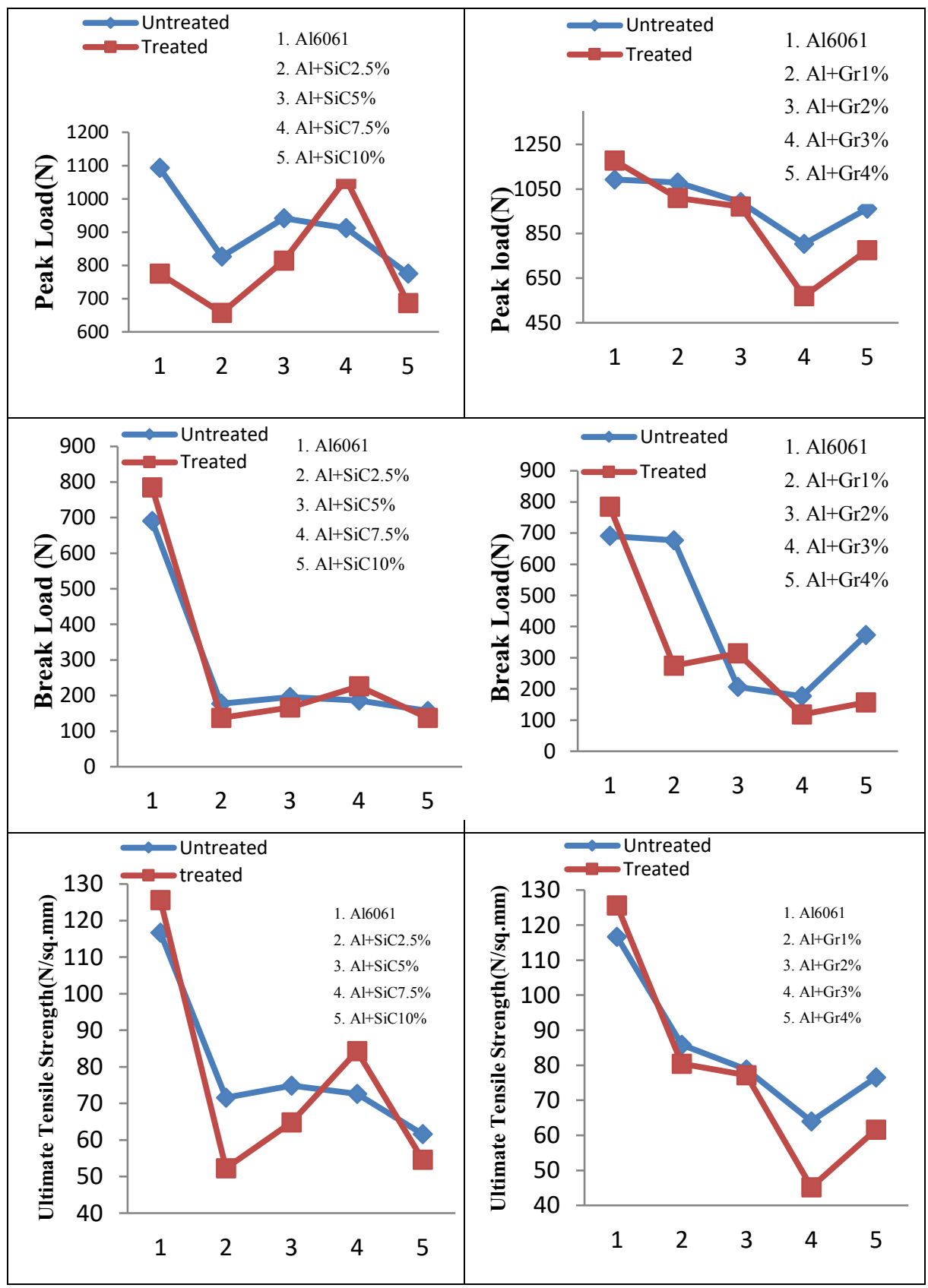

Fig. 15. Comparison of peak load, Break load and Ultimate Tensile Strength of $\mathrm{Al}+\mathrm{SiC}$ AMMCs

Fig. 16. Comparison of peak load, Break load and Ultimate Tensile Strength of $\mathrm{Al}+\mathrm{Gr}$ AMMCs 


\section{Conclusions}

1. Tensile properties improvement has shown for cryo-treated and cryo-treated $\mathrm{Al} 6061+2 \% \mathrm{Gr}$ and $\mathrm{Al} 6061+7.5 \% \mathrm{SiC}$ has optimum value. But as Gr percentage increases strength decreases.

2. Shear test shows 5-6\% improvement after cryogenic treatment

3. SEM images show a uniform distribution of reinforcement in the material after cryogenic treatment.

4. By adding $\mathrm{SiC}$ as reinforcement shows improved characteristics in cryogenic treatment but by adding Gr as reinforcement does not show any improvement in cryogenic treatment.

\section{References}

1. G. Chigal, G. saini, "Mechanical testing of Al6061/silicon carbide metal matrix composites", IJREAS Volume 2, Issue 2 February 2012 pp 221-238

2. J T. Black, Ronald A. Kohser "Materials and process in manufacturing", Text book tenth edition (2007), pg 351.

3. Seymour. G Epstein, "Aluminium and its alloys", the Aluminium association, Inc. (2001)

4. Surappa.M.K “Aluminium Matrix Composites Challenges and Opportunities", Sadhan, Vol.28, Parts 1 and 2, (2003), pp319-334

5. P. Baldissera and C. Delprete "Deep Cryogenic Treatment: A Bibliography Review" The Open Mechanical Engineering Journal,(2008), 2, 1-11

6. Ajit Behera , S.C Mishra "Comparative Study of Cryo-Treated Steel" IJSTR research volume 1, issue 7, august (2012)

7. F. Farhani, K. S. Niaki "Cryogenic treatment of metals-a review of experimental studies, underlying mechanism and process equipment" proceedings of the 4th BSMEASME ICTE 27-29 December, (2008), Dhaka, Bangladesh

8. Khalid Mahmood Ghaur, Liaqat Ali, AkhlaqAhamed, Rafiq Ahmad "Synthesis and Characterization of $\mathrm{Al} / \mathrm{SiC}$ Composite Made by Stir Casting Method" J. Engg \& Appl. Sci. Vol. 12, Jan, (2013) p.102-110 